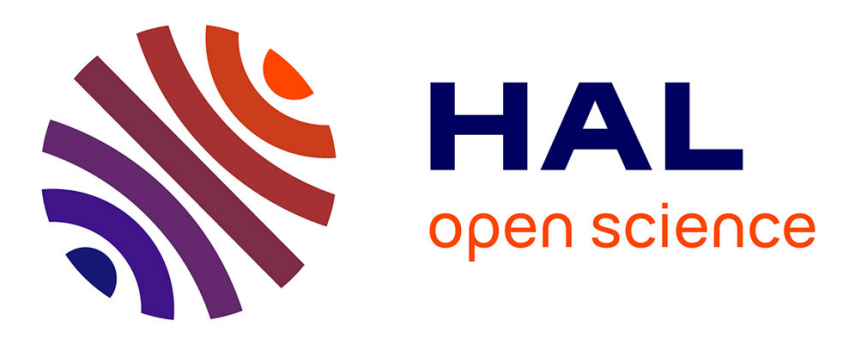

\title{
Design of Mid-IR integrated cavity based on Ge-rich graded SiGe waveguides
}

Qiankun Liu, Joan Manel Ramírez, Vladyslav Vakarin, Diego Perez-Galacho, Carlos Alonso-Ramos, Laurent Vivien, Delphine Marris-Morini, Jacopo Frigerio, Andrea Ballabio, Giovanni Isella

\section{To cite this version:}

Qiankun Liu, Joan Manel Ramírez, Vladyslav Vakarin, Diego Perez-Galacho, Carlos Alonso-Ramos, et al.. Design of Mid-IR integrated cavity based on Ge-rich graded SiGe waveguides. Photonics North, Jun 2017, Ottawa Canada. hal-01617247

\section{HAL Id: hal-01617247 https://hal.science/hal-01617247}

Submitted on 16 Oct 2017

HAL is a multi-disciplinary open access archive for the deposit and dissemination of scientific research documents, whether they are published or not. The documents may come from teaching and research institutions in France or abroad, or from public or private research centers.
L'archive ouverte pluridisciplinaire HAL, est destinée au dépôt et à la diffusion de documents scientifiques de niveau recherche, publiés ou non, émanant des établissements d'enseignement et de recherche français ou étrangers, des laboratoires publics ou privés. 


\section{Design of Mid-IR integrated cavity based on Ge-rich graded SiGe waveguides}

\author{
Qiankun Liu, Joan Manel Ramírez, Vladyslav \\ Vakarin, Diego Perez-Galacho, Carlos Alonso- \\ Ramos, Laurent Vivien, Delphine Marris-Morini \\ Centre de Nanosciences et de Nanotechnologies, CNRS \\ Univ. Paris-Sud, Université Paris Saclay, C2N-Orsay \\ 91405 Orsay cedex, France \\ E-mail: qiankun.liu@u-psud.com
}

\author{
Jacopo Frigerio, Andrea Ballabio, Giovanni Isella \\ L-NESS, Dipartimento di Fisica, Politecnico di Milano \\ Polo di Como, Via Anzani 42 \\ I 22100 Como, Italy
}

\begin{abstract}
A promising design for novel mid-infrared integrated Fabry-Perot cavities based on Bragg grating is presented. These cavities show good potential for several applications, including sensing, optical metrology, thermal imaging or free-space communications.
\end{abstract}

Keywords-mid-infrared; Si $i_{1-x} G e_{x}$ waveguide; Fabry-Perot Bragg grating cavity

\section{INTRODUCTION}

In recent years, a large variety of reported works on silicon photonics have shown the potential of this platform, which is providing high performance, low cost, low power consumption and high reliability, as a promising alternative approach to enable the integration of passive and active components at chip scale. However, most of them only focus on a narrow window of operation wavelengths that spans from the visible range up to near infrared, typically up to the telecommunication wavelength $1.55 \mu \mathrm{m}$. Currently, some research groups have proposed the use of silicon photonics not only for the visible-telecom range, but also at longer wavelengths located within the mid-IR window [1, 2]. The strong molecular absorption experienced by several relevant chemical and biological substances is providing strong motivation to the development of new chip-scale integrated mid-IR sensors.

Moreover, comparing to SOI, which transparent window related to Silicon dioxide is limited around $3.8 \mu \mathrm{m}, \mathrm{Si}$ and $\mathrm{Ge}$ offer an extended transparency window up to $8 \mu \mathrm{m}$ and $14 \mu \mathrm{m}$ respectively, which enables the design of new mid-IR devices in a broadband wavelength range. At the meanwhile, some recent works, such as the $\mathrm{Si}_{1-\mathrm{x}} \mathrm{Ge}_{\mathrm{x}}$ alloy based Mach-Zehnder interferometer and modulator operating at telecommunication wavelength $[3,4]$, also the experimental demonstration of low loss waveguide in the mid-IR range at a wavelength of $4.6 \mu \mathrm{m}$ [5], have proven the benefits of using $\mathrm{Si}_{1-\mathrm{x}} \mathrm{Ge}_{\mathrm{x}}$ alloy as an attractive platform to realize active and passive mid-IR devices. Furthermore, the flat anomalous in the whole transparent window of $\mathrm{Si}$ of this $\mathrm{Si}_{1-\mathrm{x}} \mathrm{Ge}_{\mathrm{x}}$ alloy shows good respect for non-linear optics in the mid-IR range [6].

However, in order to demonstrate the full potential of this platform some key structures still need to be developed, such

This project has received funding from the European Research Council (ERC) under the European Union's Horizon 2020 research and innovation program (grant agreement $\mathrm{N}^{\circ} 639107-$ INsPIRE). as resonant structures, which will be crucial when targeting devices for sensing applications and for the study of non-linear properties where strong light-matter interaction is desired. In that line, ring resonators entail strong challenges from a design view point taking into account the weak mode confinement in these structures. Alternatively a Fabry-Perot cavity using Bragg grating mirrors based on waveguide might be a promising option to develop mid-IR SiGe cavities with high performance. Therefore, in this work we design Bragg grating in graded $\mathrm{Si}_{1-\mathrm{x}} \mathrm{Ge}_{\mathrm{x}}$ waveguides and evaluate the performances of integrated cavities at $7.3 \mu \mathrm{m}$ wavelength.

\section{RESULTS}

The waveguide design is based on a $6 \mu$ m-thick graded $\mathrm{Si}_{1-\mathrm{x}} \mathrm{Ge}_{\mathrm{x}}$ layer that departs from $\mathrm{Si}$ and increases its $\mathrm{Ge}$ concentration up to pure Ge. The rib height is $4 \mu \mathrm{m}$ and the width is $5 \mu \mathrm{m}$ as illustrated in the inset of Fig 1. The Bragg grating is obtained by patterning the top of the waveguide with $1 \mu \mathrm{m}$ grating period and with a duty cycle of 0.5 , for operation at $7.3 \mu \mathrm{m}$ wavelength calculated by equation (1)[7].

$$
\Lambda=m \lambda_{0} / 2 n_{\text {eff }}
$$

where $\mathrm{m}$ is a positive integer which denotes the order of the grating, $\lambda_{0}$ is free-space wavelength chosen at $7.3 \mu \mathrm{m}$ and $\mathrm{n}_{\text {eff }}$ is the effective index of the guided Bloch mode.

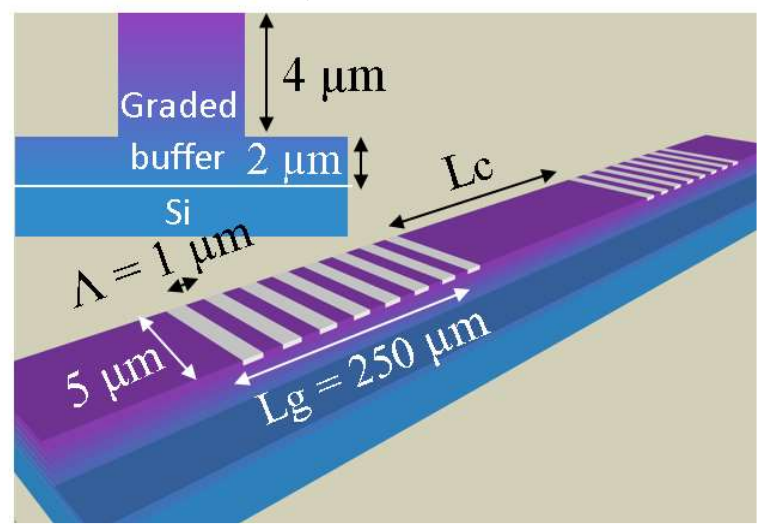

Fig 1: cross-section of waveguide and schematic view of Fabry-Perot Bragg grating cavity 
In order to avoid the bottom leakage, a maximum etch depth of $400 \mathrm{~nm}$ is used. With $250 \mu \mathrm{m}$ grating length, the reflectivity at the central wavelength per mirror is up to $93 \%$, within a $48 \mathrm{~nm}$ spectral bandwidth as shown in Fig 2.a. Based on this Bragg mirror, we successfully design the Fabry-Perot cavity with one single resonant peak and also with multiple resonant peaks, the simulated results of cavities are shown in Fig 2.b and 2.c. A $50 \mu \mathrm{m}$-long cavity shows only one single resonance around the central wavelength $7.3 \mu \mathrm{m}$, and a cavity with $600 \mu \mathrm{m}$-long cavity length shows 5 resonant peaks with a free spectral range of $10 \mathrm{~nm}$ shown in Fig.2.c. The simulation is done by using the Eigenmode expansion solver in MODE Solution.
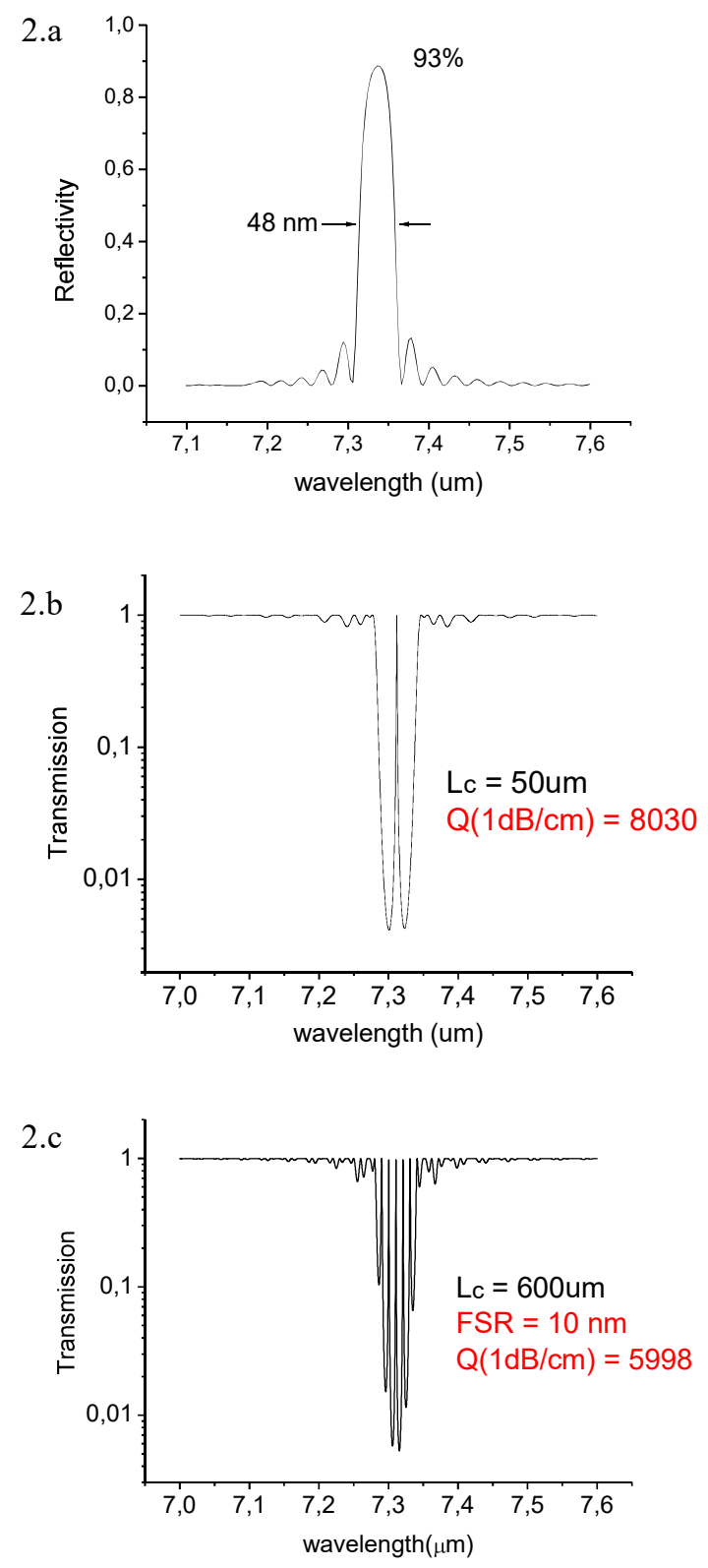

Fig 2: (a) Reflectivity of a Bragg mirror where $\Lambda=1 \mu \mathrm{m}$, $\mathrm{Lg}_{\mathrm{g}}=250 \mu \mathrm{m}$; (b) Transmission of Fabry-Perot cavity with $50 \mu \mathrm{m}$ cavity length; (c) Transmission of Fabry-Perot cavity with $600 \mu \mathrm{m}$ cavity length
Moreover, the quality factor (Q-factor) of these Fabry-Perot cavities can be estimated by

$$
\mathrm{Q}=\lambda / \delta \lambda
$$

The estimated Q-factor considering $1 \mathrm{~dB} / \mathrm{cm}$ propagation losses in the waveguide is around 8000 for the single resonance cavity and 6000 for the multi-resonances cavity. These cavities may be a fundamental building block for resonant structures targeting mid-IR integrated devices for sensing applications.

\section{ACKNOWLEDGMENT}

This project has received funding from the European Research Council (ERC) under the European Union's Horizon 2020 research and innovation program (grant agreement N639107-INsPIRE).

\section{REFERENCES}

[1] R. Soref, "Mid-infrared photonics in silicon and germanium", Nature Photonics, vol. 4, pp. 495-497, August 2010.

[2] Editorial "Extending opportunities", Nature Photonics, vol. 6, pp. 407, July 2012.

[3] V. Vakarin, P. Chaisakul, J. Frigerio, A. Ballabio, X. Le Roux, J. Coudevylle, D. Perez-Galacho, L. Vivien, D. Morini, "Sharp bends and Mach-Zehnder interferometer based on Ge-rich-SiGe waveguides on SiGe graded buffer", Optics Express, vol. 23, pp. 30821-6, Nov 2015.

[4] P. Chaisakul, D. Morini, J. Frigerio, D. Chrastina, M. Rouifed, S. Cecchi, P. Crozat, G. Isella, L. Vivien, "Integrated germanium optical interconnects on silicon substrates", Nature Photonics, vol. 8, pp. 482488, June 2014.

[5] J. Ramirez, V. Vakarin, C. Gilles, J. Frigerio, A Ballabio, P. Chaisakul, X. Le Roux, C. Alonso-Ramos, G. Maisons, L. Vivien, M. Carras, G. Isella, D. Morini, "Joan Ramirez_Low-loss Ge-rich $\mathrm{Si}_{0.2} \mathrm{Ge}_{0.8}$ waveguides formid-infrared photonics", Optics Letters, vol. 42, pp. 105108, January 2017.

[6] J. Ramirez, V. Vakarin, J. Frigerio, P. Chaisakul, D. Chrastina, X. Le Roux, A. Ballabio, L. Vivien, G. Isella, D. Morini, "Ge-rich gradedindex $\mathrm{Si}_{1-\mathrm{x}} \mathrm{Ge}_{\mathrm{x}}$ waveguides with broadband tight mode confinement and flat anomalous dispersion for nonlinear mid-infrared photonics", Optics Express, vol. 25, pp. 6561-6567, Mar 2017.

[7] E. H. Bernhardi, Thesis "Bragg-Grating-Based rare-earth-ion-doped channel waveguide lasers and their applications", Nov 2012. 